\title{
Proteomics of bovine endometrium, oocytes and early embryos
}

\author{
Daniela R. Deutsch\#, Thomas Fröhlich* and Georg J. Arnold* \\ Laboratory for Functional Genome Analysis LAFUGA, Gene Center, Ludwig-Maximilians-Universität \\ München, Munich, Germany
}

\begin{abstract}
Summary
Embryo-maternal communication, as well as recognition and establishment of pregnancy, is predominantly controlled by secretion of hormones and proteins. Furthermore, uterine fluid serves as a histotroph and contains factors essential for embryo development and elongation, making it a meaningful source for proteomic approaches of early embryonic development. The studies included in this review address the analysis of uterine fluid and endometrium during the oestrous cycle, early pregnancy, maternal effects on embryo development and embryo-induced alterations to the maternal environment. Clear differences between the proteome of uterine fluid and blood plasma unravelled the active contribution of the endometrium to the composition of uterine luminal fluid. Proteins were identified which may contribute either to growth enhancement of blastocysts or influence secretion of "Interferon tau". Several studies suggested important roles of intrauterine factors including "Tissue inhibitor of metalloproteinases 2" for pregnancy establishment and "Acyl-CoA-binding protein" for the embryo prior to implantation. A meta-analysis of quantitative proteome studies revealed functional clusters including the terms "degradation of extracellular matrix", "platelet degranulation" and "MHC class II antigen presentation". Proteomic studies targeting oocytes and early embryos provided evidence for the function of "Cyclin B" in mitotic resumption, for "14-3-3 epsilon" to activate "maturation promotion factor" for promotion of mitosis during in vitro maturation, or for the inhibition of proteasomes during the late phase of maturation. Analysis of blastocyst derived trophectoderm cell lines suggested effects of annexin down-regulation on the failure rate of nuclear transfer pregnancies. Finally, absolute quantification of "Y-box-binding protein 2" and "Insulin-like growth factor 2 mRNA-binding protein 3" during early embryogenesis by "selected reaction monitoring" demonstrated the dynamism of proteome alterations during the first embryonic cell divisions.
\end{abstract}

\section{Introduction}

The term "proteome" was introduced in 1994 by Marc Wilkins at a symposium in Sienna, Italy, as "the entire set of proteins expressed by a genome", and is now used to describe the quantitative protein pattern present under exactly defined conditions in an organism, a tissue, a cell, a cellular compartment or a body fluid. The most popular analytical method for early proteomic experiments for a long period has been two-dimensional gel electrophoresis (2D-PAGE), which was described for the first time independently in 1975 by Klose (Klose 1975) and O'Farrell (O'Farrell 1975). Since 1997, the "2D difference gel electrophoresis" (2D-DIGE) approach introduced by Unlu et al. (Unlu et al. 1997) has significantly improved reproducibility of quantification between individual 
gels and has extended the dynamic range of spot quantification by an order of magnitude. An extremely sensitive modification of the DIGE concept is based on coupling fluorophores to sulfhydryl residues in proteins to completion and referred to as 'saturation labelling' (Kondo et al. 2003). This technique facilitates analysis of complex protein mixtures using just a few micrograms of total protein (for a detailed user guide see Arnold \& Frohlich 2012).

For the last ten years, a powerful alternative to 2D gel-based approaches has been developed and is referred to as nano liquid chromatography-tandem mass spectrometry or nano-LC-MS/MS (for review see Frohlich \& Arnold 2006). In this approach, protein lysates of the original samples are digested with protease, separated by nano-chromatography (for review see Frohlich \& Arnold 2009) and subsequently analysed by a tandem mass spectrometer. For relative quantification of individual proteins in LC-MS/MS approaches, several methods are available, based on either a direct quantification of MS or MS/MS signals or on a pre-labelling of proteins or peptides with chemical tags containing different compositions of stable isotopes prior to mass spectrometry (for a detailed review of proteomic techniques see Arnold \& Frohlich 2011).

Up to now, proteomic approaches require an expensive set of instruments and sophisticated know-how with respect to protein biochemistry, chromatography, mass spectrometry and bioinformatics. Due to the variety of chemical and physicochemical properties of proteins (e.g., solubility) and the high dynamic range of $10^{8}$ in biological sources, proteins have so far not been identified and quantified on the basis of microarrays, as easily as is possible for RNAs. Probably as a consequence of the complex technology and experience required for proteomic analyses, many researchers have focused on the analysis of the transcriptome, which is much faster, cheaper and more comprehensive. However, it does not and cannot give unambiguous evidence as to whether, and to what extent, the corresponding protein is either present in the sample or is going to be synthesized. This is a consequence of the numerous regulation steps in eukaryotic organisms between the appearance of the transcript or polyA + RNA and translation at the ribosome. Making matters even more complicated, protein processing by proteolytic events, protein activation and signalling cascade activation by (de)phosphorylation is not accessible from either a genome or transcriptome. Therefore, analysis of the transcriptome is not a suitable surrogate for proteome analysis, and information about protein expression levels, abundance changes, modification stages, or activation status can in general only be gained at the protein level.

This review provides a short overview of proteomic approaches relevant for ruminant reproduction and addresses typical examples of holistic gel based and LC-MS/MS based experiments. The examples describe applications of proteomic techniques to bovine endometrium, uterine laminar fluid, oocytes and early embryos and illustrate the power of current methods to decipher complex biological processes at a molecular level. As a forward look, we include an unpublished example from our laboratory illustrating the unprecedented power of this developing technology "Selected reaction monitoring" (SRM) (for review see Frohlich \& Arnold 2011), a universally applicable, highly sensitive and antibody free quantification technique for targeted proteomic approaches.

\section{Role of the uterine environment during early pregnancy}

In beef and milk production, early embryonic mortality is an important factor leading to enormous economic losses. In cattle, the majority of embryo losses happens before Day 16 after conception (Diskin \& Morris 2008). Failure to maintain pregnancy during early stages of gestation can be caused by incorrect embryonic development, insufficient receptivity of the uterus, or be a consequence of an impaired biochemical communication between the conceptus and the maternal environment (Wolf et al. 2003). In cattle, the early embryo enters the uterus around Day 
5 after fertilization (Hackett et al. 1993). From then on, in addition to embryo quality, the uterine environment plays a major role in the successful establishment and maintenance of pregnancy. Until embryo attachment around Day 19, the embryo develops to a blastocyst, hatching on Day 9 to 10 and continuing to grow and elongate to a conceptus with a tubular shape of $10-20 \mathrm{~cm}$ in length (Betteridge \& Fléchon 1988). During this phase, the embryo/conceptus is surrounded by and dependent on the uterine fluid (Morris \& Diskin 2008), which contains minerals, nutrients, vitamins and proteins. At this stage of pregnancy, progesterone released by the corpus luteum $(\mathrm{CL})$ is a key hormone, modulating the endometrium and enabling growth as well as elongation of the conceptus. In ruminants, the conceptus secretes interferon tau (IFNT) (Mann et al. 1999, Spencer et al. 2008) in order to maintain CL progesterone secretion and to prevent luteolysis. IFNT interacts with endometrial receptors, leading to a decrease of estrogen receptors and, as a consequence, to decreased estrogen-induced oxytocin receptor expression. These IFNT induced effects subsequently hinder prostaglandin F2-alpha release, luteolysis and a resumption of the oestrous cycle (Thatcher et al. 2001). In cattle, IFNT production in the trophectoderm rises around Day 11 and reaches a maximum around Day 16, leading to maternal recognition of pregnancy (Mann et al. 1999). Although these crucial processes are well known, further biochemical mechanisms controlling receptivity and embryo implantation are still poorly understood. The analysis of the embryo-maternal interface with modern "-omics" technologies (Ulbrich et al. 2013) generate sophisticated datasets increasing the understanding of the biochemical processes taking place during early pregnancy. A variety of transcriptomic studies have been published, addressing alterations in gene expression of endometrium during the oestrous cycle (Bauersachs et al. 2008, Bauersachs et al. 2005), early pregnancy (Bauersachs et al. 2006, Bauersachs \& Wolf 2012, Klein et al. 2006), as well as clarifying further effects of key molecules like progesterone (Forde et al. 2011, Forde et al. 2012). However, since the establishment of pregnancy is predominantly controlled by secretory events, proteome analysis of the uterine milieu to which the early embryo/ conceptus is exposed is particularly interesting. The broad majority of proteomic studies performed so far have targeted human uterine proteins in the context of diseases like endometrial/cervical cancer, endometriosis, and the diagnosis of infertility and will not be a focus of this review (for comprehensive reviews please refer to Meehan et al. 2010, Salamonsen et al. 2013). The use of proteomic techniques to study the uterine environment of ruminants during the oestrous cycle and early pregnancy has a long history. During the 1980s and 90s, endometrium, uterine luminal fluids (ULF), as well as uterine/endometrial secreted proteins of goat (Gnatek et al. 1989, Weise et al. 1993), sheep (Lee et al. 1998, Moffatt et al. 1993) and cow (Rueda et al. 1993) were analysed. However, the majority of these early studies were impaired by the fact that the sensitive and effective identification of proteins by mass spectrometry was not routinely available at that time. For the bovine system, the majority of more recent studies focused on ULF. Until implantation the embryo is surrounded by this fluid which serves as a supply of nutrients, minerals and vitamins. It is clear that this uterine histotroph represents a promising target for the detection and identification of proteins important for the survival and growth of the early embryo. Furthermore, ULF is the matrix facilitating the transport of signal molecules crucial for the molecular communication between the maternal environment and the conceptus (Ulbrich et al. 2012).

\section{Modulation of the ULF proteome during oestrous cycle}

It is known from various species that ULF contains blood proteins, as well as proteins secreted by the uterine epithelium (Fischer \& Beier 1986, Kayser et al. 2006, Lee et al. 1998, Roberts \& Parker 1974). Therefore, a quantitative proteome study was performed in order to detect proteins differing in abundance between both biological fluids (Faulkner et al. 2012). Using an 8-plex 
iTRAQ approach, the authors compared proteomes of uterine flushes from ipsilateral $(n=6)$ and contralateral $(n=6)$ uterine horns with blood plasma $(n=4)$ of cyclic Day 7 beef heifers. To increase analytical depth of the proteome analysis, the samples were albumin depleted, leading to a quantification of 112 proteins. In total, 35 of these proteins had higher and 18 had lower abundance in the uterine flush samples compared with plasma. In the dataset of higher abundant proteins in plasma, several with protease inhibitor functionality could be identified. Among the higher abundant proteins in ULF, various proteins involved in carbohydrate metabolism (e.g. aldose reductase (AKR1B1), a variety of proteins associated with response to stress, proteins with roles in the immune system and transport proteins like acyl-CoA-binding protein $(\mathrm{DBI})$ were identified. Since the proteome of uterine fluid differs significantly from the plasma proteome, the authors concluded that the endometrium contributes actively to the ULF composition and may be regulated and influenced by other factors like local steroid stimuli.

The modulation of ULF composition during the oestrous cycle and the strong impact of ULF on the growth of the bovine embryo has been further demonstrated by an experiment performed by Ledgard and coworkers (Ledgard et al. 2012). In their study, they transferred Day 7 IVP blastocysts either to synchronous Day 7 or to asynchronous Day 5 and Day 9 uteri. The embryos were recovered on either Day 14 or Day 22. Comparing the developmental parameters of conceptuses after Day 14, they found that their average length was halved in case of transfer on Day 5, or increased fourfold in the case of transfer at Day 9, compared to conceptuses generated by artificial insemination (AI). On Day 22, the development of blastocysts transferred at Day 5 remained retarded, whereas differences of conceptuses derived from blastocysts transferred at Day 9 were less pronounced. To detect differences between Day 5, Day 7 and Day 9 in ULF at the proteome level, they performed 2D-PAGE experiments and identified 10 proteins where their abundance was altered between Day 5 and 9 of oestrous cycle, three of which were subsequently verified by Western blot experiments. All three proteins i) aldose reductase (AK1R1B1), ii) phosphoserine aminotransferase 1 (PSAT1) and iii) purine nucleoside phosphorylase (PNP) were enriched in uterine flushes obtained from Day 9 animals. Furthermore, legumain (LGMN) and tissue inhibitor of metalloproteinases 2 (TIMP2) were detected by Western blots exclusively in Day 14 ULF. This finding is in agreement with the distinct increase of TIMP2 protein in uterine fluid at Day 15 of oestrous cycle observed in a previous study (Ulbrich et al. 2011). In summary, the authors concluded that the growth enhancement of blastocysts transferred to uteri at Day 9 was correlated with the expression of several proteins. These proteins may contribute to the growth of the conceptus trophectoderm and positively influence the secretion of IFNT crucial for pregnancy establishment.

The dynamic character of the ULF proteome during the oestrous cycle was further investigated by a study performed by Mullen and coworkers (Mullen et al. 2012). They quantitatively analysed uterine flushes from Day 7 and Day 13 cyclic heifers ( $n=6$ per group), with the goal to identify proteins contributing to early embryo survival. In total, 300 proteins were identified from Day 7 samples and 510 proteins from Day 13 samples, of which 281 were present in both groups. To quantitatively compare the results, a spectral counting approach was applied and led to the detection of 5 proteins of higher abundance at Day 7 and 29 proteins which were more abundant on Day 13. Bioinformatics and literature studies revealed that among the proteins enriched at Day 13 several are related to metabolism, tissue remodelling, embryo growth/development, uterine health/immune function and free radical management. LGMN, TIMP2, chromogranin A (CHGA) and superoxide dismutase (SOD) were further validated by Western blotting. The authors concluded that the temporal proteome signatures detected in Day 7 and Day 13 uterine fluids may be used as markers associated with uterine health and receptivity as well as with embryo development. Importantly more abundant proteins on Day 
13 may have a role for embryo growth. Furthermore, the study is in-line with results of previous publications (Ledgard et al. 2012, Ulbrich et al. 2011), all of which support an important role of intrauterine TIMP2 for pregnancy establishment.

A further LC-MS based proteomic approach compared proteomes of Day 7 ULF with Day 15 ULF (Faulkner et al. 2013). In contrast to Mullen et al. (2012), they divided the samples into two further groups with respect to the plasma progesterone concentration of the donors at Day 5. For proteome analysis, the 8-plex iTRAQ strategy, including internal pooled standards, was used, leading to identification of 167 proteins in four or more biological replicates. No significant differences in abundance between the ULF proteomes between the high and low progesterone groups were detected. Nevertheless, the abundance of several proteins correlated with plasma progesterone concentrations. In addition, 20 proteins showed higher abundance at Day 15 compared to Day 7, and another 20 proteins showed lower abundance at Day 15. Among the proteins enriched at Day 15, LGMN, TIMP2, retinol binding protein 4 (RBP4) and isocitrate dehydrogenase 1 (IDH1) could be identified. The authors concluded that progesterone - as well as the cycle stage during early embryonic development - modulates the abundance of proteins related to similar functions. Furthermore, the study represents an excellent complement to other proteomic approaches described in this review investigating the role of ULF during the oestrous cycle.

\section{Alterations of ULF proteome prior to pregnancy recognition at Day 16}

Since the uterine environment prior to pregnancy recognition at Day 16 may not exclusively be modulated by maternal factors, some proteome studies studied the ULF proteome in the presence of early embryos. A 2D-gel based study analysed uterine fluid of beef heifers in either the presence or absence of embryos (Munoz et al. 2012). For sample generation, 29 to 56 morulae (Day 5) were transferred to the animals and flushed at Day 8. To eliminate the effects of genetic variability, the same animals were used for Day 5 sham transfers and flushed at Day 8. Furthermore, the animals were used for Al experiments and embryo transfers of single embryos to obtain further samples and to check if these procedures impaired the ability of the animals to become pregnant. The proteomes of uterine flushes $(n=8$ per group) were analysed using a 2D-DIGE approach, leading to the identification of 38 proteins where abundance was altered. Although the changes in abundance of many of these proteins were fairly low, (the majority of the proteins showed differences in abundance lower than 1.5), bioinformatic analysis suggested an involvement of NFאB pathway. In addition, the authors performed further validation and more targeted experiments, e.g. Western blots, embryo culture in either the presence or absence of uterine fluid dialysates, and immunocytochemical analysis of embryos. These data led to the hypotheses that the downregulated NFKB pathway in the uterus may contribute to the immune privilege of the early embryo, and that TNF $\alpha$ and IL-1B could be involved as embryonic signalling molecules.

A recently published proteomic study addressed ULF during early pregnancy (Beltman et al. 2014) and analysed the uterine histotroph of heifers at Day 7 after insemination. Uterine flushes were grouped into those derived from heifers with viable embryos (either morula or early blastocyst stage) and those from heifers with degenerate embryos arrested at the 2- to 16-cell stage ( $n=3$ per group). A 2D-LC-MS/MS approach, combined with spectral counting, was used for quantitative proteome analysis, and 40 proteins were identified from which 6 significantly differed in abundance. Five of these proteins, namely tubulins beta-4A (TUBB4A) and alpha-1D (TUBA1D), cytochrome c1 (CYC1), dihydropyrimidinase-related protein 2 
(DPYSL2) and platelet-activating factor acetylhydrolase IB subunit gamma (PAFAH1B3) were more abundant in flushes from the group having viable embryos, whereas S100-A4 was less abundant. S100-A4 is involved in the regulation of a variety of cellular processes, amongst them cell differentiation and cell cycle progression. The authors suggested that the identified proteins may serve as markers for the successful development of early embryos. It was suggested that PAFAH1B3, belonging to the group of platelet-activating factors - known to play an important role for embryo development in other species, may represent a focus for further studies.

\section{Embryo-induced proteomic alterations in the uterine milieu after maternal recognition of pregnancy but prior to implantation}

Just before implantation, molecular signalling between the embryo and endometrium appears to be crucial for the maintenance of pregnancy. For instance, as well as the suppression of prostaglandin F2-alpha release and CL luteolysis, the maternal immune system must be influenced to become tolerant to the immunologically 'foreign' conceptus (Bauersachs \& Wolf 2013). To investigate the embryo maternal communication just before embryo implantation, Ledgard and co-workers analysed Day 16 and Day 18 ULF of pregnant (Day 16, $\mathrm{n}=3$; Day 18, $\mathrm{n}=2$ ) and non-pregnant (Day 16, $\mathrm{n}=2$; Day 18, $\mathrm{n}=3$ ) dairy cows using 2D-PAGE (Ledgard et al. 2009). In a gel based comparison of ULF from non-pregnant donors with ULF originating from the uterine horn ipsilateral and contralateral to the embryo, nine higher abundant ( $>2$-fold) proteins in pregnant versus non-pregnant donors were detected. Mass spectrometry led to the identification of peroxiredoxin 1 (PRDX1), carbonic anhydrase, thioredoxin (TXN), ezrin (EZR), heat shock protein 70 (HSP70), IDH dehydrogenase (IDH), nucleoside diphosphate kinase (NDPK), purine nucleoside phosphorylase (PNP), and triosephosphate isomerase (TPI1). Furthermore, four proteins, i.e. LGMN, TIMP2, retinol-binding protein (RBP) and cystatin E/M (CST6), were more abundant in ULF from non-gravid donors and from horns contralateral to the conceptus. Two of these proteins, LGMN and TIMP2, were analysed in more detail by Western blots of caruncular tissue and ULF samples. Furthermore, endometrial LGMN and TIMP2 mRNA levels during the oestrous cycle were monitored and localized by in situ hybridisation, and the corresponding proteins were localized by immunocytochemistry. Interestingly, it was demonstrated that LGMN and TIMP-2 mRNA expression was quite similar between uterine horns during early pregnancy, but that the corresponding protein abundance was significantly decreased in horns containing a conceptus. The authors speculated that the amount of these proteins may be modulated by IFNT or other factors secreted by the conceptus. This is a clear example demonstrating that protein abundance cannot be extrapolated from mRNA levels. Furthermore, the study identified a number of specific proteins which may be involved in conceptus-maternal interactions prior to placentation.

One of the few studies investigating the proteome of endometrial tissue during the periimplantation stage was performed by our group (Berendt et al. 2005) with the focus on Day 18 of pregnancy. To reduce genetic variability as a cause of proteome differences, we used monozygotic cattle twins (generated by embryo splitting). One twin ( $n=3$ per group) received two in vitro-produced blastocysts at Day 7, whereas the other twin received a sham-transfer as a non-pregnant control. Using 2D-DIGE technology, intercaruncular endometrium samples from the pregnant and corresponding non-pregnant twin were analysed. Image analysis of the 2D-gels and subsequent mass spectrometry led to the identification of four proteins of higher abundance (ratio $\geq 2$, p-values $<10^{-5}$ ) in the endometrium of pregnant animals: i) Rho GDP dissociation inhibitor 2 (ARHGDIB) ii) isocitrate dehydrogenase 1 (IDH1) iii) acyl-CoA-binding protein (DBI) and iv) aldose reductase (AKR1B1), referred to as 20 Alpha-hydroxysteroid dehydrogenase. The abundance of 
AK1RB1 was further validated in all replicates by a mass spectrometry based approach using the cleavable isotope-coded affinity tag (ICAT). Noticeably, three of these proteins were also detected in other studies discussed and cited in this review. For example IDH1, an essential enzyme of the Krebs cycle, was found to be enriched in Day 15 ULF compared to Day 7 ULF (Faulkner et al. 2013) and was shown to be more abundant in ULF of animals at Day 18 of pregnancy (Ledgard et al. 2009). Furthermore, acyl-CoA-binding protein (DBI), which binds medium- and long-chain acyl-CoA esters with very high affinity, was found to be enriched by a factor $>7$ in Day 7 ULF compared to plasma (Faulkner et al. 2012), strongly suggesting an important role of this protein in the embryo prior to implantation. Another finding supporting the importance of $\mathrm{DBI}$ was reported in mice, where DBI-null embryos are not able to achieve the blastocyst stage (Landrock et al. 2010). A further protein identified in several proteomic studies investigating the bovine uterine environment is AKR1B1. AK1RB1 is known to be a key enzyme for the conversion of glucose to sorbitol, the first step in the polyol pathway. In addition to our finding, AKR1B1 was i) found to be enriched in Day 7 ULF compared to plasma (Faulkner et al. 2012), was ii) detected in higher abundance in ULF at Day 9 and Day 14 compared to Day 5 (Ledgard et al. 2012), was iii) identified in Day 7 ULFs in groups with viable and degenerate embryos (Beltman et al. 2014) and iv) identified in Day 7 and Day 13 ULF samples (see supporting information in Mullen et al. 2012). The importance of this enzyme is further supported by additional findings in other species (Lee et al. 1998, Ross et al. 2007).

All the endometrium related proteome studies presented above have provided new insights into the complex biochemical processes of pregnancy establishment. The uterine proteins, of which alterations in abundance were detected so far, represent valuable targets for functional studies. To create a functional overview of these proteins, we performed a combined Cytoscape/ ClueGO/CluePedia analysis (Bindea et al. 2013, Bindea et al. 2009, Smoot et al. 2011) for all the proteins in which an alteration in abundance in either the ULF or the endometrium during the oestrous cycle or early pregnancy was detected in at least one of the studies. The two most prominent clusters are shown in Fig. 1. Interestingly, the ClueGO analysis revealed an enrichment of proteins related to the terms "Degradation of the cellular matrix", "Platelet degranulation", "Activation of Chaperones by IRE1alpha", "Glycosphingolipid metabolism" and "MHC class II antigen presentation". Notably, the formation of these clusters is based on different studies addressing different time points of the oestrous cycle and early pregnancy. This demonstrates that studies investigating multiple time points during early pregnancy are necessary to comprehensively describe the uterine milieu at the proteome level. The knowledge and understanding about the uterine proteome is still far from being complete. However, future studies, making use of the newest developments in mass spectrometry, will allow a deeper understanding of the uterine proteome, and contribute substantially to the unravelling of the biochemical processes crucial for bovine pregnancy establishment.

\section{Quantitative proteome analysis of oocyte maturation and early embryogenesis}

Though mammalian oocytes and embryos have been extensively investigated, only a few have so far taken a proteomic approach. Moreover, most of those studies were performed in mice, and results can only be extrapolated to both non-rodent mammals and humans to a very limited extent because of the fundamental differences in their reproductive physiology and morphology. Furthermore, both cattle and humans are monovulatory and the duration of oestrous and menstrual cycle are significantly longer (21 and 28 days, respectively). The physiology, morphology and size of the ovaries and oocytes are also very similar between humans and cows (Gordon 2003, 


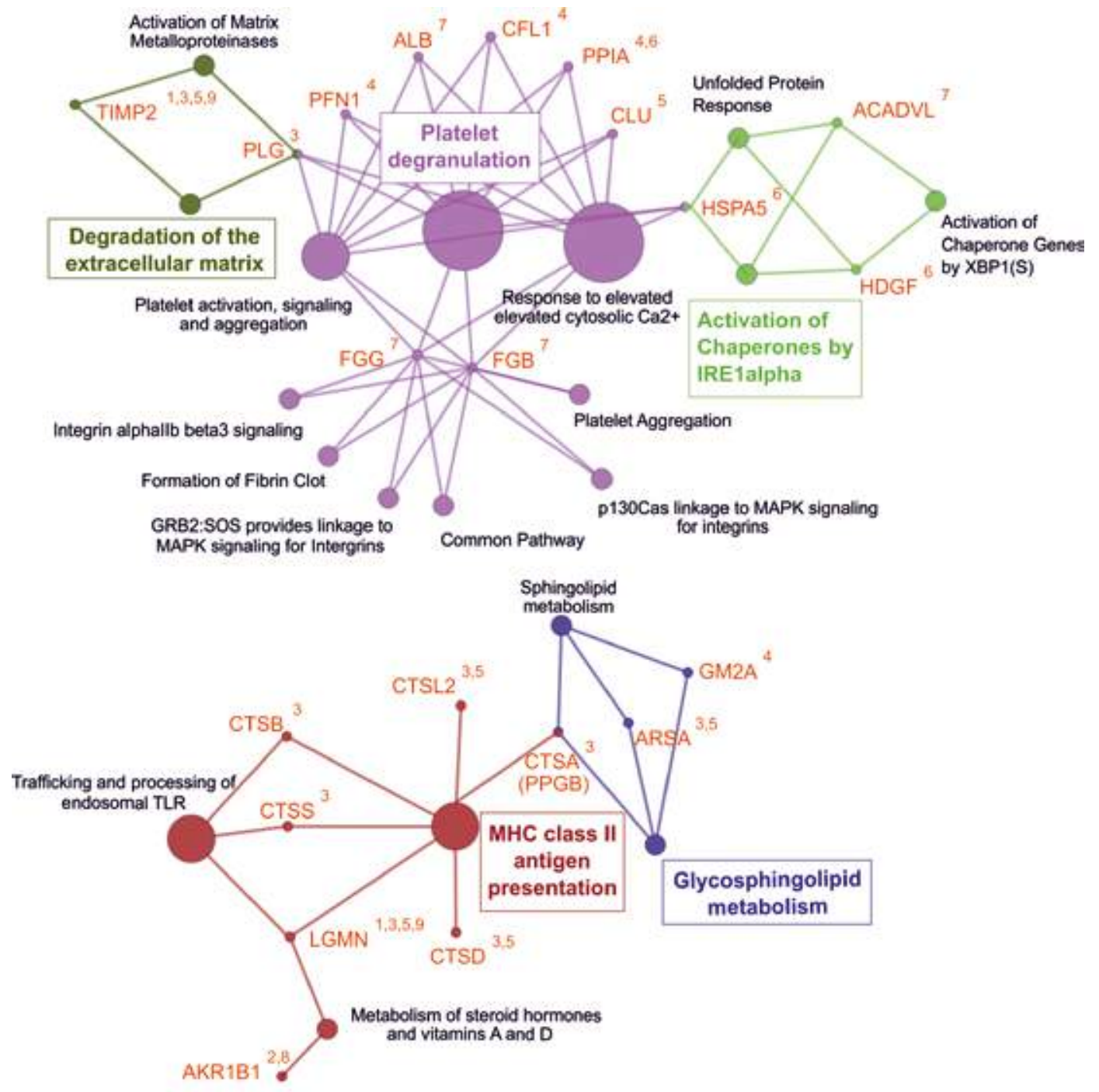

\begin{tabular}{|l|l|}
\hline 1 & Increased in ULF of cycle Day 14 compared to Day 5 and Day 9 (Ledgard et al. 2012) \\
\hline 2 & Increased in ULF of cycle Day 9 and Day 14 compared to Day 5 (Ledgard et al. 2012) \\
\hline 3 & Increased in ULF of cycle Day 13 compared to Day 7 (Mullen et al. 2012) \\
\hline 4 & increased in ULF of cycle Day 7 compared to Day 15 (Faulkner et al. 2013) \\
\hline 5 & increased in ULF of cycle Day 15 compared to Day 7 (Faulkner et al. 2013) \\
\hline 6 & increased in ULF at Day 8 after embryo transfer (Munoz et al. 2012) \\
\hline 7 & Decreased in ULF at Day 8 after embryo transfer (Munoz et al. 2012) \\
\hline 8 & increased in the endometrium of Day 18 pregnant animals (Berendt et al. 2005) \\
\hline 9 & Decreased in ULF of horns containing Day 18 conceptus (Ledgard et al. 2009) \\
\hline
\end{tabular}

Fig. 1. ClueGO / CluePedia analysis of proteins shown to be altered in abundance in either ULF or endometrium during the oestrous cycle or early pregnancy. Enriched terms from the Reactome database are displayed as nodes. The node size corresponds to the statistical significance (adjusted p-value) for each term. Gene symbols of the corresponding proteins are shown as small circles and are connected to related terms from the Reactome database. 
Guzman et al. 2012). Therefore, besides addressing problems in ruminant reproduction and development, bovine oocytes and embryos can in a number of aspects also serve as animal models for human reproduction and corresponding disorders and/or therapies (Hall et al. 2013), making research in this area especially valuable. The following discussion highlights some recent research covering this field. As a convenient overview, key results of each study, together with IDs of the altered proteins are shown in Table 1.

Table 1. Summary of proteomic studies concerning bovine oocyte maturation and early embryogenesis.

\begin{tabular}{|c|c|}
\hline $\begin{array}{l}\text { Study subject / } \\
\text { approach }\end{array}$ & Major findings \\
\hline $\begin{array}{l}\text { Oocyte maturation/ } \\
\text { radiolabelling + } \\
2 \text { D-PAGE }\end{array}$ & Identification of cyclin B \\
\hline $\begin{array}{l}\text { Oocyte maturation/ } \\
\text { radiolabelling + } \\
\text { 2D-PAGE }\end{array}$ & $\begin{array}{l}\text { Characteristic patterns of protein } \\
\text { synthesis detected }\end{array}$ \\
\hline $\begin{array}{l}\text { Oocyte maturation/ } \\
\text { 2D-PAGE }\end{array}$ & $\begin{array}{l}40 \text { proteins identified; } 4 \text { were } \\
\text { differentially expressed: tubulin-chain } \\
\text { (TBB), cyclin E2 (CCNE2) and truncated } \\
\text { CCNE2, protein disulfide isomerase } \\
\text { (PDIA3), and peroxiredoxin } 2 \text { (PDX2) }\end{array}$ \\
\hline $\begin{array}{l}\text { Oocyte maturation/ } \\
\text { 2D-DIGE saturation } \\
\text { labelling }\end{array}$ & $\begin{array}{l}38 \text { significant differences in protein } \\
\text { abundance between GV and MII } \\
\text { oocytes; } 10 \text { identified: clusterin } \\
\text { (CLU), translationally controlled } \\
\text { tumour protein (TCTP), E2, } \\
\text { 6-phosphogluconolactonase (6PGL), } \\
\text { peroxiredoxin-3 (PRDX3), Eukaryotic } \\
\text { translation (EF-1 } 1 \gamma \text { ), and 14-3-3 protein } \\
\text { epsilon (YWHAE) and } 3 \text { different } \\
\text { isoforms of glutathione-s-transferase Mu } \\
5 \text { (GSTM5) }\end{array}$ \\
\hline
\end{tabular}

Oocyte maturation/ 669 proteins identified and 653

iTRAQ labelling + quantified; relative abundance of 7 and LC-MS/MS

Embryogenesis/ radiolabelling + 1D-PAGE

Oocyte maturation + embryogenesis/ radiolabelling + 2D-PAGE

Trophectoderm cell lines / 2D-PAGE + MALDI-TOF-MS or LC-MS/MS response to the proteasomal inhibitor MG132, respectively

Protein synthesis decreased between the zygote and the 8-cell stage and then increased until the blastocyst staged

46 proteins present during oocyte maturation as well as early embryogenesis; 10 identified: HSC71, HSP70, CypA, UCH-L1, GSTM5, Cct5, E-FABP, 2,3-BPGM, E2D3 and $ß$-actin/ $\gamma$-actin
Conclusions

Cyclin B may have an initiator role

for meiotic resumption

Protein synthesis affects different proteins during the transition of GV to MIl stage; 3 patterns of protein synthesis detected

CCNE2 and PDX2 as molecular markers for meiotic maturation suggested

Reference

Levesque \&

Sirard 1996

Coenen et al. 2004

Bhojwani et al. 2006

Varying abundance changes between different isoforms of GSTM5 revealed; Decrease of YWHAE fits MPF activation to promote mitosis; Protein candidates for in vitro maturation suggested

Berendt et al. 2009

Inhibition of proteasomes during the late phase of oocyte maturation You et al. can improve the developmental competence of oocytes

The maternal-to-embryonic transition occurs at the 8-16-cell stage

Translation affects different proteins during oocyte maturation and embryogenesis; Housekeeping proteins suggested

2012b

Frei et al. 1989

Massicotte et al. 2006

Down-regulation of annexin genes in cultured NT-derived trophectoderm cell lines may play a role in the high failure rate of nuclear transfer pregnancies 


\section{Quantitative proteome analysis of oocyte maturation}

The earliest molecular approaches investigating qualitative and quantitative changes in the proteome of bovine oocytes addressed alterations of protein profiles during in vitro oocyte maturation. Radiolabelling approaches, combined with one-dimensional electrophoresis, were used to assess de novo protein synthesis as well as protein phosphorylation patterns. They demonstrated that maturation is associated with the synthesis of distinct and temporally expressed proteins (Kastrop et al. 1990, Khatir et al. 1998, Wu et al. 1996). Due to the lack of sensitive mass spectrometry based protein identification methods at that time, quantitative changes in protein synthesis rates could be assessed, but not assigned to individual protein IDs. One of the first proteins identified using a proteomic approach was cyclin B. This protein was suggested to have an initiator role in meiotic resumption and was identified by comparison of two-dimensional (2D) gel patterns of de novo synthesized proteins involved in meiotic resumption (Levesque \& Sirard 1996).

In a more recent study, the process of oocyte maturation was investigated with respect to de novo protein synthesis during a $28 \mathrm{~h}$ period using a radiolabelling approach ${ }^{35} \mathrm{~S}$-methionine) and 2D gel separation (Coenen et al. 2004). Cumulus-oocyte complexes were incubated in conventional maturation medium and metabolically labelled at seven different time points over $24 \mathrm{~h}$. The proteins of the denuded oocytes were separated using 2D-PAGE, autoradiograms of $2 \mathrm{D}$ gels were scanned and optical density of protein spots used as a quantitative measure of de novo protein synthesis. A comparison between the seven $4 \mathrm{~h}$ time intervals revealed three major patterns of protein synthesis: one at the beginning of maturation $(0-4 \mathrm{~h})$, one in the middle (4$16 \mathrm{~h}$ ), and a further one after the completion of MI stage (16-28 h), demonstrating that protein synthesis affects different proteins during the transition of GV to MII stage. Interestingly, the number of synthesized proteins was highest at the beginning of maturation until the MI stage, and then decreased after $12 \mathrm{~h}$ and then stayed fairly constant.

In a further 2D gel based approach, differentially expressed proteins involved in meiotic maturation of oocytes were identified and their phosphorylation pattern assessed (Bhojwani et al. 2006). Bovine oocyte extracts from 400 oocytes, each in either the GV (0 h), MI (10 h), or MII (24 h) stages were treated either with or without the cyclin dependent kinases (CDK) inhibitor butyrolactone I (BL I), subjected to 2D-PAGE and stained with Sypro Ruby. For staining of phosphoproteins, the fluorescent Pro-Q diamond phosphoprotein gel stain was applied, which makes it possible to distinguish between phosphorylated and non-phosphorylated proteins (Peluso \& Pappalardo 2004, Steinberg et al. 2003). In total, 4800 bovine oocytes were analysed in three independent series of experiments from which 550 protein spots could be detected using Sypro Ruby-stained gels at any given maturation stage. On ProQ diamond-stained gels, 190 spots in GV stage, 270 spots in MII stage, and 250 in MII and after treatment with BL I were observed. There is increasing evidence that meiotic resumption is under the control of CDK1 kinase, which forms the maturation promoting factor MPF together with cyclin B, and mitogen-activated protein kinases MAPK (for review see Fan \& Sun 2004, Kishimoto 2003). BL I is supposed to impair resumption of meiosis due to its CDK-inhibiting quality. In a preceding study (Tomek et al. 2002), the group had already demonstrated that BL I inhibits phosphorylation of essential components of the translation initiation complex and therefore modulates translation. Nevertheless, BL I treatment seemed to have no apparent effect on the overall expression of proteins during IVM in the follow-up study (Bhojwani et al. 2006) and the authors conclude, that alterations in the proteome are mainly caused by protein degradation and not by changes in the turnover of proteins. From ProQ diamond staining, a phosphorylation ratio of $30 \%$ at the GV stage, $50 \%$ at the MI stage and $45 \%$ at the MII stage was estimated. Seven proteins were claimed to be differentially phosphorylated between the stages and the phosphorylation of 
peroxiredoxin-2 responded to BL I treatment, suggesting control via MPF or MAPK. To identify the proteins separated on the gels, Sypro Ruby stained spots were picked, digested with trypsin and analysed with MALDI-TOF-MS. Spots were only considered significant when differences in spot intensities were greater than a factor of two. Forty spots could be identified and four of them were differentially abundant, from which cyclin E2 and peroxiredoxin-2 were suggested to serve as molecular markers for meiotic maturation (Bhojwani et al. 2006).

A very sensitive non-radioactive protein labelling method, 2D-DIGE saturation labelling, was applied to study bovine oocyte maturation in vitro (Berendt et al. 2009). In this 2D gel-based approach, two overlapping $\mathrm{pH}$ gradients $(\mathrm{pH} 4-7$ and $\mathrm{pH} 6-9)$ were used to detect and quantify more than 3000 protein spots by fluorescence scanning from a total protein amount of only $0.5 \mu \mathrm{g}$ per gel, which equals about six oocytes. Six biological replicates were analysed which led to the detection of 38 significant differences in protein abundance $(p<0.01$ in Student's t-test, abundance ratio $>2$ ) between GV and MII oocytes. Of these 38 spots, the intensities of 21 increased during maturation, while the intensities of 17 decreased. A preparative gel of saturation-labelled protein extracts from 2200 oocytes rendered it possible to identify differentially abundant proteins of matched spots by nano-LC-MS/MS analysis. Among the proteins decreasing in abundance during maturation were clusterin (CLU), translationally controlled tumour protein (TCTP), peroxiredoxin-3 (PRDX3), and 14-3-3 protein epsilon (YWHAE). The latter has been suggested to mediate Cdc25 phosphatase inhibition (Yang et al. 1999), which is a phosphatase required for MPF activation (Yurttas et al. 2010). A particular advantage of 2D gel-based proteomics is the possibility to detect changes between different isoforms of proteins. The 2D-DIGE saturation labelling approach by Berendt et al. revealed changes in abundance of different isoforms of glutathione-s-transferase Mu 5 (GSTM5). While two isoforms (pl values 5.3 and 5.5) increased by a factor of 10.3 and 2.7, respectively, a third isoform (pl value 6.3) was decreased by a factor of 4.1. 2D-DIGE-based protein quantification was verified by Western blotting and validated by confocal laser scanning microscopy.

A recently published study (You et al. 2012b) used a nano-LC-MS/MS approach in combination with iTRAQ labelling to analyse the effect of the proteasomal inhibitor MG132 during bovine oocyte maturation. The proteasome is a multisubunit proteolytic complex (for review see Tanaka 2013) and early in maturatio, completion of meiosis I requires an inactivation of MPF through proteasomal cleavage of ubiquitinated cyclin B1 (for review see Karabinova et al. 2011). Treatment of oocytes with MG132 late in maturation had been shown to improve developmental competence of parthenogenetically activated oocytes in the pig (You et al. 2012a). To test the effect of MG132 in the cattle, You et al. applied the inhibitor between $16 \mathrm{~h}$ to $22 \mathrm{~h}$ after initiation of maturation. Proteomic analysis from three biological replicates was performed by labelling 100 ug of tryptic peptides of oocyte proteins per sample with iTRAQ and separating the peptides by an off-line 2D-LC method (SCX followed by RP chromatography) coupled to a Q-TOF MS/MS system. A total of 669 proteins were identified in MII oocytes, and 653 proteins could be quantified. Exposure to MG132 increased the abundance of six proteins (minimum abundance ratio $>1.2$ or $<0.8 ; \mathrm{p}<0.05$ using Fisher's combined probability test). These comprised of glyceraldehyde-3-phosphate dehydrogenase (GAPDH), an enzyme involved in glycolysis and related to developmental competence (Krisher \& Bavister 1999), tubulin alpha-1C chain (TUBA1C), important for organellar movement (Rivera et al. 2004), proteins involved in protein folding, and protein disulfide-isomerase (P4HB), which is an anti-apoptotic protein (Hashida et al. 2011). The abundance of 23 proteins was decreased, among them several proteins that exert anti-apoptotic actions and cyclin-dependent kinase 5 (CDK5), which can lead to apoptosis if aberrantly activated (Lopes et al. 2010). Finally, the study demonstrated that treatment with MGF132 late in maturation improves oocyte competence in cattle. 


\section{Quantitative proteome analysis of early embryogenesis}

Several recent transcriptomic studies have studied bovine embryogenesis (Gad et al. 2012, Graf et al. 2014, Kues et al. 2008), but there are only few studies that have used proteomic approaches. One of the earliest studies using molecular approaches investigated quantitative changes in the proteome of bovine embryos, using radiolabelled ${ }^{35} S$-methionine and one-dimensional electrophoresis. The amount of de-novo protein synthesis during early embryogenesis was found to decrease between the zygote and the 8-cell stage and then to increase until the blastocyst stage (Frei et al. 1989). These results helped to determine the time of the maternal-to-embryonic transition (MET) (for review see Memili \& First 2000).

Another study in bovine embryos (Massicotte et al. 2006) aimed to identify the maternal housekeeping proteins (MHKP) translated during bovine oocyte maturation and early embryo development. The group radiolabelled bovine oocytes and cultured embryos in presence of $\alpha$-amanitine $15 \mathrm{~h}$ post-insemination (hpi), which limited protein synthesis to translation of maternal mRNAs (Plante et al. 1994). Embryos were then radiolabelled for $4 \mathrm{~h}$ between $36-40 \mathrm{hpi}$ at the 2-cell stage, 48-52 hpi at the 4-cell stage and 60-64 hpi at the 8-cell stage. Pools of 10 embryos were prepared for 2D-gel analysis. For protein identification, a preparative gel containing $3000 \mathrm{GV}$ oocytes was prepared. It was demonstrated, that 92 proteins were synthesized de novo throughout oocyte maturation and a total of 123 proteins during all three stages of embryogenesis. 46 proteins were synthesized during maturation as well as embryogenesis and were therefore considered as possible MHKPs. Using mass spectrometry, 10 of these potential MHKPs were identified, including the heat shock $70 \mathrm{kDa}$ protein (HSP70), ubiquitin carboxyl-terminal hydrolase isozyme L1 (UCH-L1) and bisphosphoglycerate mutase (2,3-BPGM). Furthermore, pattern analysis of de novo translated proteins demonstrated a transition period until the embryo reaches the MET.

\section{Proteomic analysis of trophectoderm cell lines established from bovine blastocysts}

The mammalian blastocyst develops three distinct cell lineages before implantation, i.e., the epiblast, the endoderm and the trophectoderm. The latter forms the outer epithelial layer of the blastocyst which becomes the trophoblast of the placenta (for review see Rossant 2008). The regulation of the formation and maintenance of the trophectoderm has been widely studied in mammalian embryos (for review see Yamanaka et al. 2006), and trophectoderm has been used for the generation of cell lines. A recent study (Talbot et al. 2010) analysed different trophectoderm cell lines established from 8-11 day cattle embryos and examined differences in their proteome by 2D-gel electrophoresis combined with either MALDI-TOF-MS or LC-MS/MS. Trophectoderm cell lines were established from either in vivo-produced blastocysts $(n=5)$ or from in vitro-produced blastocysts derived by either in vitro maturation, fertilization and culture $(\mathrm{IVF}, \mathrm{n}=16)$, somatic cell nuclear transfer $(\mathrm{NT}, \mathrm{n}=16)$ or parthenogenetic $(\mathrm{P})$ activation $(\mathrm{n}=12)$ of oocytes. The success rate of cell line establishment was similar regardless of the source of blastocysts, except for in vivo-derived blastocysts, which had 100\% efficiency. Comparison of gels led to the identification of 118 common protein spots of which $95 \%$ were identified. It was demonstrated that both of the calcium-dependent lipid-binding proteins, annexin I and II, were either reduced in abundance $(p \leq 0.05)$, or even absent, in NT-derived trophectoderm cell lines compared to IVF- and P-derived cell lines. Several proteomic studies of cow and pig placentas revealed that annexins and annexin interacting proteins, like S100, are modulated when compared to normal control placentas (Chae et al. 2006, Kim et al. 2005, Lee et al. 2007). It was suggested by Talbot et al. (2010) that down-regulation of annexin genes in cultured NT-derived trophectoderm cell lines may play a role in causing the high failure rate of nuclear transfer pregnancies. 


\section{Selected Reaction Monitoring - a new and highly sensitive method for proteomics}

A recently established method called Selected Reaction Monitoring (SRM) allows pre-selected proteins to be measured in a targeted approach in significantly smaller samples consisting of one to ten oocytes or embryo per analysis (Frohlich \& Arnold 2011, Lange et al. 2008, Picotti et al. 2010). Our group is currently developing a multiplexed SRM assay for simultaneous quantification of developmentally relevant proteins (Deutsch et al., unpublished data). As a proof of concept, we established SRM assays for Y-box-binding protein 2 (YBX2) and IGF2 mRNAbinding protein 3 (IGF2BP3), which we had previously detected in embryos at the 2-cell and 4-cell stages (Demant et al., unpublished data). YBX2 has been reported to have an important role in storage and translational regulation of maternal mRNAs (Vigneault et al. 2009). The IGF2BP family influences the cytoplasmic fate of mRNAs (Fig. 2) and modulates cellular function and morphology, metabolism, proliferation and differentiation during development. IGF2BPs are highly expressed in both embryos and metastatic tissue (for review see Bell et al. 2013).

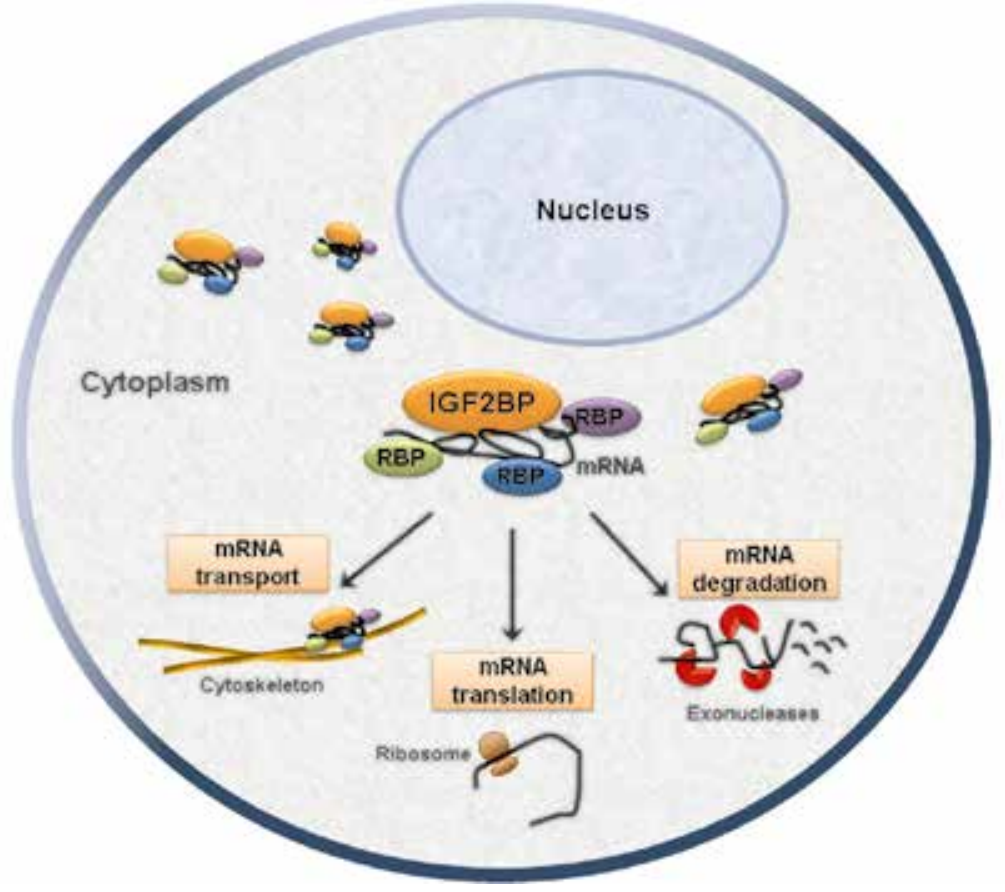

Fig. 2. Functions of the IGF2BP family. IGF2BPs regulate the cytoplasmic fate of mRNAs together with other RNA-binding proteins (RBPs). RBPs associate with specific target mRNAs (insulin-like growth factor II, ß-actin and proto-oncogene c-Myc), which are supposed to enable directed transport of transcripts throughout the cell along the microtubule and/or actin cytoskeleton. Adapted from Bell et al. 2013.

For absolute quantification, pools of GV oocytes, 2-cell embryos, 4-cell embryos and morulae were digested and measured on a QTrap mass spectrometer. Addition of stable isotope labelled synthetic peptide standards (so-called AQUA ${ }^{\mathrm{TM}}$ peptides) corresponding to the peptides of interest enabled absolute protein quantitation. A typical SRM chromatogram illustrating the quantification of YBX2 and IGF2BP3 in a protein extract from $10 \mathrm{GV}$ oocytes is shown in Fig. 3.

A total of $20 \mathrm{fmol}$ AQUA peptide each was added and the three most intense transitions of each measured peptide, either endogenous or AQUA, are illustrated. The ratio between the most intense transitions, called quantifier, of endogenous and AQUA peptides was used 


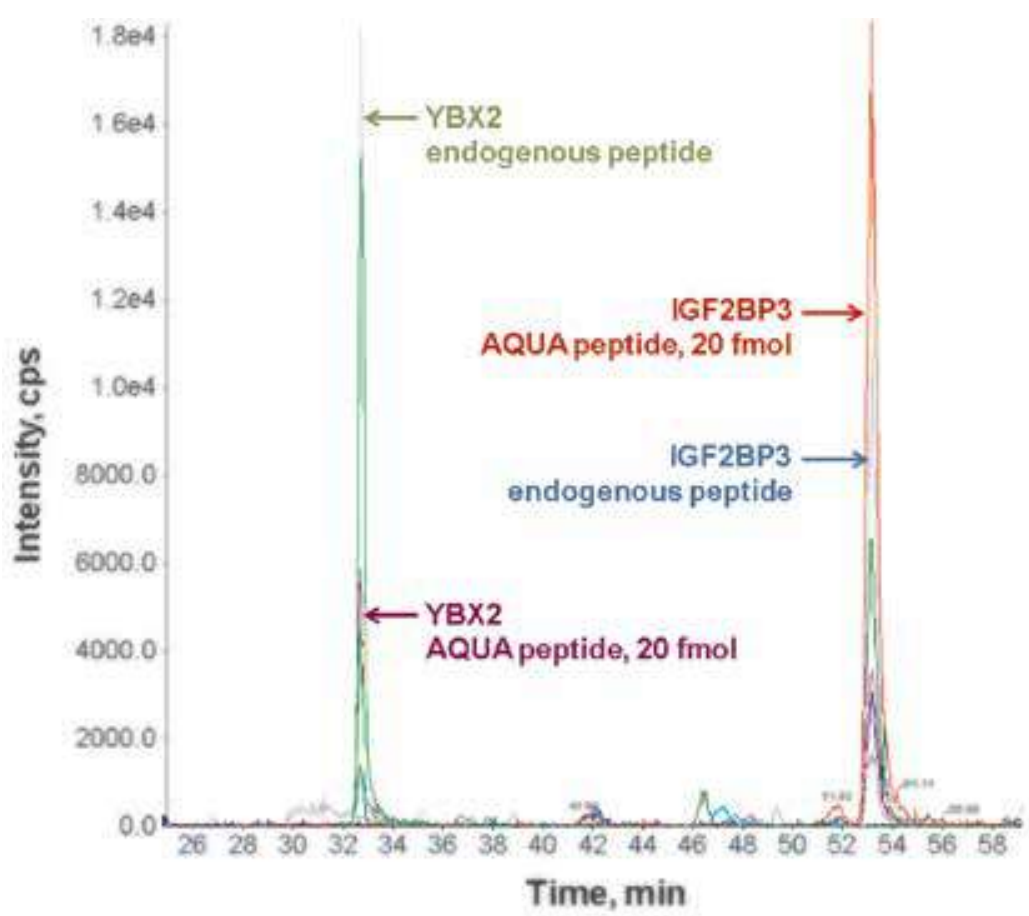

Fig. 3. SRM chromatogram of a simultaneous quantification of GAEAANVTGPGGVPVK of Y-box-binding protein 2 (YBX2) and IPVSGPFLVK of IGF2 mRNA-binding protein 3 (IGF2BP3) in a pool of $10 \mathrm{GV}$ oocytes with $20 \mathrm{fmol}$ AQUA peptide each. The quantifier transitions (fragment y3 for YBX2 and fragment y7 for IGF2BP3, both charged [2+]) are indicated by arrows. The remaining coloured lines represent two additional transitions serving as qualifiers for each endogenous peptide / AQUA peptide. Y-axis: Intensity of SRM signals in counts per second; $x$-Axis: Chromatographic retention time in minutes.

A Y-box-binding protein 2 (YBX2)

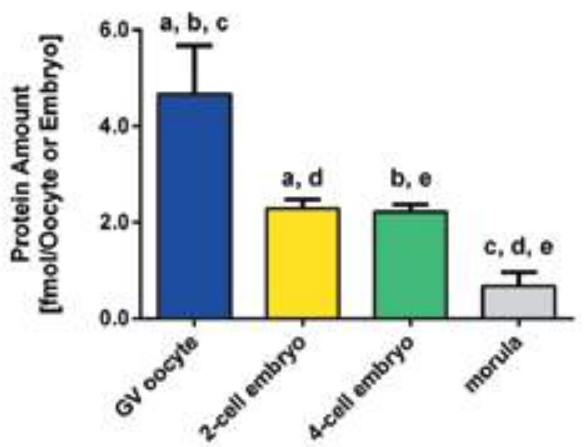

B IGF2 mRNA-binding protein 3 (IGF2BP3)

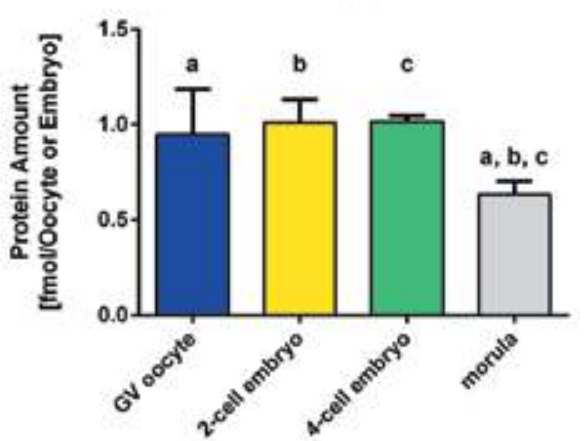

Fig. 4. Absolute SRM based quantification of Y-box-binding protein 2 (YBX2) and IGF2 mRNA-binding protein 3 (IGF2BP3). YBX2 and IGF2BP3 were quantified simultaneously in pools of 10 oocytes or embryos each. Absolute protein amounts are represented as fmol per oocyte or embryo (mean $\pm \mathrm{SD}$, $\mathrm{n}=3$ ). A Mann-Whitney test was performed with GraphPad Prism 6 software and demonstrates statistically significant differences ( $p$-value $<0.05$ ):

Panel A: YBX2 content of GV oocytes versus 2-cell embryos, 4-cell embryos and morula (a, b, c), 2-cell embryos and 4-cell embryos versus morula $(d, e)$;

Panel B: IGF2BP3 content of GV oocytes, 2-cell and 4-cell embryos versus morula (a, b, c). 
to calculate absolute protein amounts per oocyte or embryo. The results are presented in Fig. 4. GV oocytes contained about $5 \mathrm{fmol}$ YBX2 per oocyte, and the YBX2 content significantly decreased during development from GV oocytes to 2-cell embryos, remained constant at about $2 \mathrm{fmol}$ per embryo during the next cell division to a 4-cell embryo, and decreased further to about $1 \mathrm{fmol}$ per embryo during morula formation. The high amount of YBX2 in GV oocytes and the restricted window of YBX2 expression are consistent with the function of this protein in storage and translational regulation of maternal mRNAs (Vigneault et al. 2009). The amount of IGF2BP3 protein remained constant at a concentration of about $1 \mathrm{fmol}$ per oocyte or embryo up to the 4-cell stage and decreased significantly during transition from the 4-cell embryo to the morula stage to about 600 amol per embryo. This suggests IGF2BP3 has a particularly important role in RNA trafficking and translational control during very early embryogenesis until at least the 4-cell stage. These results demonstrate the considerable dynamics in the abundance of proteins with even low abundance at stages of embryogenesis which, from a morphological point of view, seem to only redistribute the molecular environment of the inner cell mass to increasing numbers of blastomeres.

\section{Conclusions / Outlook}

In conclusion, the approaches described demonstrate impressively the power of modern proteomic techniques and approaches to effectively discover and quantify proteins crucial for ruminant reproduction. Furthermore, bioinformatic methods can facilitate in the functional assignment to either signal transduction and/or biochemical pathways. Proteomics continues to contribute substantially to the discovery and improved understanding of key physiological processes relevant in early development.

In the future, proteomics is expected to have an even greater impact on the understanding in life sciences as its rapidly evolving analytical power is increased even further. Ongoing technical developments in mass spectrometry and protein separation techniques will lead to considerably increased sensitivity and performance, facilitating more comprehensive proteome datasets from even smaller sample quantities. Moreover, the recently developed antibody free SRM technology enables highly sensitive protein quantification in the attomole range, and thus opens up the field of protein science to more quantitative approaches across all animal species. With respect to mammalian reproduction, the ultimate ambition of comprehensive proteomic analysis in single oocytes and embryos will soon be affordable, leading to significantly increased and rapid understanding of the processes in ruminant early development.

\section{References}

Arnold GJ \& Frohlich T 2011 Dynamic proteome signatures in gametes, embryos and their maternal environment. Reprod Fertil Dev 23 81-93.

Arnold GJ \& Frohlich T 2012 2D DIGE saturation labeling for minute sample amounts. Methods Mol Biol 854 89-112.

Bauersachs S, Mitko K, Ulbrich SE, Blum H \& Wolf E 2008 Transcriptome studies of bovine endometrium reveal molecular profiles characteristic for specific stages of estrous cycle and early pregnancy. Exp Clin Endocrinol Diabetes 116 371-384.

Bauersachs S, Ulbrich SE, Gross K, Schmidt SE, Meyer HH, Einspanier R, Wenigerkind H, Vermehren M, Blum H,
Sinowatz F \& Wolf E 2005 Gene expression profiling of bovine endometrium during the oestrous cycle: detection of molecular pathways involved in functional changes. J Mol Endocrinol 34 889-908.

Bauersachs S, Ulbrich SE, Gross K, Schmidt SE, Meyer HH, Wenigerkind H, Vermehren M, Sinowatz F, Blum H \& Wolf E 2006 Embryo-induced transcriptome changes in bovine endometrium reveal species-specific and common molecular markers of uterine receptivity. Reproduction 132 319-331.

Bauersachs S \& Wolf E 2012 Transcriptome analyses of bovine, porcine and equine endometrium during the 
pre-implantation phase. Anim Reprod Sci 134 84-94.

Bauersachs S \& Wolf E 2013 Immune aspects of embryomaternal cross-talk in the bovine uterus. I Reprod Immunol 97 20-26.

Bell JL, Wachter K, Muhleck B, Pazaitis N, Kohn M, Lederer M \& Huttelmaier S 2013 Insulin-like growth factor 2 mRNA-binding proteins (IGF2BPs): post-transcriptional drivers of cancer progression? Cell Mol Life Sci 70 2657-2675.

Beltman ME, Mullen MP, Elia G, Hilliard M, Diskin MG, Evans AC \& Crowe MA 2014 Global proteomic characterization of uterine histotroph recovered from beef heifers yielding good quality and degenerate day 7 embryos. Domest Anim Endocrinol 46 49-57.

Berendt FJ, Frohlich T, Bolbrinker P, Boelhauve M, Gungor T, Habermann FA, Wolf E \& Arnold GJ 2009 Highly sensitive saturation labeling reveals changes in abundance of cell cycle-associated proteins and redox enzyme variants during oocyte maturation in vitro. Proteomics 9 550-564.

Berendt FJ, Frohlich T, Schmidt SE, Reichenbach HD, Wolf E \& Arnold GJ 2005 Holistic differential analysis of embryo-induced alterations in the proteome of bovine endometrium in the preattachment period. Proteomics 5 2551-2560.

Betteridge KJ \& Fléchon JE 1988 The anatomy and physiology of pre-attachment bovine embryos. Theriogenology 29 155-187.

Bhojwani M, Rudolph E, Kanitz W, Zuehlke H, Schneider F \& Tomek W 2006 Molecular analysis of maturation processes by protein and phosphoprotein profiling during in vitro maturation of bovine oocytes: a proteomic approach. Cloning Stem Cells 8 259-274.

Bindea G, Galon J \& Mlecnik B 2013 CluePedia Cytoscape plugin: pathway insights using integrated experimental and in silico data. Bioinformatics 29 661-663.

Bindea G, Mlecnik B, Hackl H, Charoentong P, Tosolini M, Kirilovsky A, Fridman WH, Pages F, Trajanoski Z \& Galon J 2009 ClueGO: a Cytoscape plug-in to decipher functionally grouped gene ontology and pathway annotation networks. Bioinformatics 25 1091-1093.

Chae JI, Cho SK, Seo JW, Yoon TS, Lee KS, Kim JH, Lee KK, Han YM \& Yu K 2006 Proteomic analysis of the extraembryonic tissue from cloned porcine embryos. Mol Cell Proteomics 5 1559-1566.

Coenen K, Massicotte L \& Sirard MA 2004 Study of newly synthesized proteins during bovine oocyte maturation in vitro using image analysis of two-dimensional gel electrophoresis. Mol Reprod Dev 67 313-322.

Diskin MG \& Morris DG 2008 Embryonic and early foetal losses in cattle and other ruminants. Reprod Domest Anim 43 Suppl 2 260-267.

Fan HY \& Sun QY 2004 Involvement of mitogen-activated protein kinase cascade during oocyte maturation and fertilization in mammals. Biol Reprod 70 535-547.

Faulkner S, Elia G, Mullen MP, O'Boyle P, Dunn MJ \& Morris D 2012 A comparison of the bovine uterine and plasma proteome using iTRAQ proteomics. Proteomics 12 2014-2023.

Faulkner S, Elia G, P OB, Dunn M \& Morris D 2013
Composition of the bovine uterine proteome is associated with stage of cycle and concentration of systemic progesterone. Proteomics 13 3333-3353.

Fischer B \& Beier HM 1986 Uterine Environment in Early Pregnancy. In JM Sreenan and MG Diskin (ed.), Embryonic Mortality in Farm Animals, pp. 93-108. Springer Netherlands.

Forde N, Beltman ME, Duffy GB, Duffy P, Mehta JP, O'Gaora P, Roche JF, Lonergan P \& Crowe MA 2011 Changes in the endometrial transcriptome during the bovine estrous cycle: effect of low circulating progesterone and consequences for conceptus elongation. Biol Reprod 84 266-278.

Forde N, Mehta JP, Minten M, Crowe MA, Roche JF, Spencer TE \& Lonergan P 2012 Effects of low progesterone on the endometrial transcriptome in cattle. Biol Reprod 87124.

Frei RE, Schultz GA \& Church RB 1989 Qualitative and quantitative changes in protein synthesis occur at the 8-16-cell stage of embryogenesis in the cow. J Reprod Fertil 86 637-641.

Frohlich T \& Arnold GJ 2006 Proteome research based on modern liquid chromatography - tandem mass spectrometry: separation, identification and quantification. Journal of Neural Transmission 113 973-994.

Frohlich T \& Arnold GJ 2009 A newcomer's guide to nanoliquid-chromatography of peptides. Methods Mol Biol 564 123-141.

Frohlich T \& Arnold GJ 2011 Quantifying attomole amounts of proteins from complex samples by nano-LC and selected reaction monitoring. Methods $\mathrm{Mol}$ Biol 790 141-164.

Gad A, Hoelker M, Besenfelder U, Havlicek V, Cinar U, Rings F, Held E, Dufort I, Sirard MA, Schellander K \& Tesfaye D 2012 Molecular mechanisms and pathways involved in bovine embryonic genome activation and their regulation by alternative in vivo and in vitro culture conditions. Biol Reprod 87100.

Gnatek GG, Smith LD, Duby RT \& Godkin JD 1989 Maternal recognition of pregnancy in the goat: effects of conceptus removal on interestrus intervals and characterization of conceptus protein production during early pregnancy. Biol Reprod 41 655-663.

Gordon IR 2003 Laboratory Production of Cattle Embryos: CABI Pub.

Graf A, Krebs S, Zakhartchenko V, Schwalb B, Blum H \& Wolf E 2014 Fine mapping of genome activation in bovine embryos by RNA sequencing. Proc Natl Acad Sci U S A 111 4139-4144.

Guzman L, Ortega-Hrepich C, Albuz FK, Verheyen G, Devroey P, Smitz J \& De Vos M 2012 Developmental capacity of in vitro-matured human oocytes retrieved from polycystic ovary syndrome ovaries containing no follicles larger than 6 mm. Fertil Steril 98 503-507.e501-502.

Hackett AJ, Durnford R, Mapletoft RJ \& Marcus GJ 1993 Location and status of embryos in the genital tract of superovulated cows 4 to 6 days after insemination. Theriogenology 40 1147-1153.

Hall V, Hinrichs K, Lazzari G, Betts DH \& Hyttel P 2013 Early embryonic development, assisted reproductive technologies, and pluripotent stem cell biology in 
domestic mammals. The Veterinary Journal 197 128-142.

Hashida T, Kotake Y \& Ohta S 2011 Protein disulfide isomerase knockdown-induced cell death is cell-linedependent and involves apoptosis in MCF-7 cells. J Toxicol Sci 36 1-7.

Karabinova P, Kubelka M \& Susor A 2011 Proteasomal degradation of ubiquitinated proteins in oocyte meiosis and fertilization in mammals. Cell Tissue Res 346 1-9.

Kastrop PM, Bevers MM, Destree OH \& Kruip TA 1990 Changes in protein synthesis and phosphorylation patterns during bovine oocyte maturation in vitro. J Reprod Fertil 90 305-310.

Kayser JP, Kim JG, Cerny RL \& Vallet JL 2006 Global characterization of porcine intrauterine proteins during early pregnancy. Reproduction 131 379-388.

Khatir H, Lonergan P \& Mermillod P 1998 Kinetics of nuclear maturation and protein profiles of oocytes from prepubertal and adult cattle during in vitro maturation. Theriogenology 50 917-929.

Kim HR, Kang JK, Yoon JT, Seong HH, Jung JK, Lee HM, Sik Park C \& Jin DI 2005 Protein profiles of bovine placenta derived from somatic cell nuclear transfer. Proteomics 5 4264-4273.

Kishimoto T 2003 Cell-cycle control during meiotic maturation. Curr Opin Cell Biol 15 654-663.

Klein C, Bauersachs S, Ulbrich SE, Einspanier R, Meyer HH, Schmidt SE, Reichenbach HD, Vermehren M, Sinowatz F, Blum H \& Wolf E 2006 Monozygotic twin model reveals novel embryo-induced transcriptome changes of bovine endometrium in the preattachment period. Biol Reprod 74 253-264.

Klose J 1975 Protein mapping by combined isoelectric focusing and electrophoresis of mouse tissues. A novel approach to testing for induced point mutations in mammals. Humangenetik 26 231-243.

Kondo T, Seike M, Mori Y, Fujii K, Yamada T \& Hirohashi S 2003 Application of sensitive fluorescent dyes in linkage of laser microdissection and two-dimensional gel electrophoresis as a cancer proteomic study tool. Proteomics 3 1758-1766.

Krisher RL \& Bavister BD 1999 Enhanced glycolysis after maturation of bovine oocytes in vitro is associated with increased developmental competence. Mol Reprod Dev 53 19-26.

Kues WA, Sudheer S, Herrmann D, Carnwath JW, Havlicek V, Besenfelder U, Lehrach H, Adjaye J \& Niemann H 2008 Genome-wide expression profiling reveals distinct clusters of transcriptional regulation during bovine preimplantation development in vivo. Proc Natl Acad Sci U S A 105 19768-19773.

Landrock D, Atshaves BP, McIntosh AL, Landrock KK, Schroeder F \& Kier AB 2010 Acyl-CoA binding protein gene ablation induces pre-implantation embryonic lethality in mice. Lipids 45 567-580.

Lange V, Picotti P, Domon B \& Aebersold R 2008 Selected reaction monitoring for quantitative proteomics: a tutorial. Mol Syst Biol 4222.

Ledgard AM, Berg MC, McMillan WH, Smolenski G \& Peterson AJ 2012 Effect of asynchronous transfer on bovine embryonic development and relationship with early cycle uterine proteome profiles. Reprod Fertil Dev 24 962-972.

Ledgard AM, Lee RS \& Peterson AJ 2009 Bovine endometrial legumain and TIMP-2 regulation in response to presence of a conceptus. Mol Reprod Dev 76 65-74.

Lee RS, Wheeler TT \& Peterson AJ 1998 Large-format, two-dimensional polyacrylamide gel electrophoresis of ovine periimplantation uterine luminal fluid proteins: identification of aldose reductase, cytoplasmic actin, and transferrin as conceptus-synthesized proteins. Biol Reprod 59 743-752.

Lee SY, Park JY, Choi YJ, Cho SK, Ahn JD, Kwon DN, Hwang KC, Kang SJ, Paik SS, Seo HG, Lee HT \& Kim JH 2007 Comparative proteomic analysis associated with term placental insufficiency in cloned pig. Proteomics 7 1303-1315.

Levesque JT \& Sirard MA 1996 Resumption of meiosis is initiated by the accumulation of cyclin B in bovine oocytes. Biol Reprod 55 1427-1436.

Lopes JP, Oliveira CR \& Agostinho P 2010 Neurodegeneration in an Abeta-induced model of Alzheimer's disease: the role of Cdk5. Aging Cell 9 64-77.

Mann GE, Lamming GE, Robinson RS \& Wathes DC 1999 The regulation of interferon-tau production and uterine hormone receptors during early pregnancy. J Reprod Fertil Suppl 54 317-328.

Massicotte L, Coenen K, Mourot M \& Sirard MA 2006 Maternal housekeeping proteins translated during bovine oocyte maturation and early embryo development. Proteomics 6 3811-3820.

Meehan KL, Rainczuk A, Salamonsen LA \& Stephens AN 2010 Proteomics and the search for biomarkers of female reproductive diseases. Reproduction 140 505-519.

Memili E \& First NL 2000 Zygotic and embryonic gene expression in cow: a review of timing and mechanisms of early gene expression as compared with other species. Zygote 8 87-96.

Moffatt RJ, Bettencourt CM \& Keisler DH 1993 Endocrine and endometrial secretory protein changes associated with uterine receptivity in sheep. Domest Anim Endocrinol 10 117-126.

Morris D \& Diskin M 2008 Effect of progesterone on embryo survival. Animal 2 1112-1119.

Mullen MP, Elia G, Hilliard M, Parr MH, Diskin MG, Evans AC \& Crowe MA 2012 Proteomic characterization of histotroph during the preimplantation phase of the estrous cycle in cattle. J Proteome Res 11 3004-3018.

Munoz M, Corrales FJ, Caamano JN, Diez C, Trigal B, Mora MI, Martin D, Carrocera S \& Gomez E 2012 Proteome of the early embryo-maternal dialogue in the cattle uterus. J Proteome Res 11 751-766.

O'Farrell PH 1975 High resolution two-dimensional electrophoresis of proteins. J.Biol.Chem. $2504007-4021$.

Peluso JJ \& Pappalardo A 2004 Progesterone regulates granulosa cell viability through a protein kinase G-dependent mechanism that may involve 14-3-3sigma. Biol Reprod 71 1870-1878.

Picotti P, Rinner O, Stallmach R, Dautel F, Farrah T, Domon B, Wenschuh H \& Aebersold R 2010 High-throughput generation of selected reaction-monitoring assays for 
proteins and proteomes. Nat Methods 7 43-46.

Plante L, Plante C, Shepherd DL \& King WA 1994 Cleavage and $3 \mathrm{H}$-uridine incorporation in bovine embryos of high in vitro developmental potential. Mol Reprod Dev 39 375-383.

Rivera RM, Kelley KL, Erdos GW \& Hansen PJ 2004 Reorganization of microfilaments and microtubules by thermal stress in two-cell bovine embryos. Biol Reprod 70 1852-1862.

Roberts GP \& Parker JM 1974 Macromolecular components of the luminal fluid from the bovine uterus. J Reprod Fertil 40 291-303.

Ross JW, Ashworth MD, White FJ, Johnson GA, Ayoubi PJ, DeSilva U, Whitworth KM, Prather RS \& Geisert RD 2007 Premature estrogen exposure alters endometrial gene expression to disrupt pregnancy in the pig. Endocrinology 148 4761-4773.

Rossant J 2008 Stem cells and early lineage development. Cell 132 527-531.

Rueda BR, Naivar KA, George EM, Austin KJ, Francis H \& Hansen TR 1993 Recombinant interferon-tau regulates secretion of two bovine endometrial proteins. J Interferon Res 13 303-309.

Salamonsen LA, Edgell T, Rombauts LJF, Stephens AN, Robertson DM, Rainczuk A, Nie G \& Hannan NJ 2013 Proteomics of the human endometrium and uterine fluid: a pathway to biomarker discovery. Fertility and sterility 99 1086-1092.

Smoot ME, Ono K, Ruscheinski J, Wang PL \& Ideker T 2011 Cytoscape 2.8: new features for data integration and network visualization. Bioinformatics 27 431-432.

Spencer TE, Sandra O \& Wolf E 2008 Genes involved in conceptus-endometrial interactions in ruminants: insights from reductionism and thoughts on holistic approaches. Reproduction 135 165-179.

Steinberg TH, Agnew BJ, Gee KR, Leung WY, Goodman T, Schulenberg B, Hendrickson J, Beechem JM, Haugland RP \& Patton WF 2003 Global quantitative phosphoprotein analysis using Multiplexed Proteomics technology. Proteomics 3 1128-1144.

Talbot NC, Powell AM, Caperna TJ \& Garrett WM 2010 Proteomic analysis of the major cellular proteins of bovine trophectoderm cell lines derived from IVP, parthenogenetic and nuclear transfer embryos: Reduced expression of annexins I and II in nuclear transfer-derived cell lines. Anim Reprod Sci 120 187-202.

Tanaka K 2013 The proteasome: from basic mechanisms to emerging roles. Keio J Med 62 1-12.

Thatcher WW, Guzeloglu A, Mattos R, Binelli M, Hansen TR \& Pru JK 2001 Uterine-conceptus interactions and reproductive failure in cattle. Theriogenology 56 14351450.

Tomek W, Melo Sterza FA, Kubelka M, Wollenhaupt K, Torner H, Anger M \& Kanitz W 2002 Regulation of translation during in vitro maturation of bovine oocytes: the role of MAP kinase, elF4E (cap binding protein) phosphorylation, and elF4E-BP1. Biol Reprod 66 12741282.
Ulbrich SE, Groebner AE \& Bauersachs S 2013 Transcriptional profiling to address molecular determinants of endometrial receptivity--lessons from studies in livestock species. Methods 59 108-115.

Ulbrich SE, Meyer SU, Zitta K, Hiendleder S, Sinowatz F, Bauersachs S, Buttner M, Frohlich T, Arnold GJ, Reichenbach HD, Wolf E \& Meyer HH 2011 Bovine endometrial metallopeptidases MMP14 and MMP2 and the metallopeptidase inhibitor TIMP2 participate in maternal preparation of pregnancy. Mol Cell Endocrinol 332 48-57.

Ulbrich SE, Wolf E \& Bauersachs S 2012 Hosting the preimplantation embryo: potentials and limitations of different approaches for analysing embryo-endometrium interactions in cattle. Reprod Fertil Dev 25 62-70.

Unlu M, Morgan ME \& Minden JS 1997 Difference gel electrophoresis: a single gel method for detecting changes in protein extracts. Electrophoresis 18 2071-2077.

Vigneault C, McGraw S \& Sirard MA 2009 Spatiotemporal expression of transcriptional regulators in concert with the maternal-to-embryonic transition during bovine in vitro embryogenesis. Reproduction 137 13-21.

Weise DW, Newton GR \& Emesih GC 1993 Effects of day of the estrous cycle or pregnancy on protein secretion by caprine endometrial tissues. Biol Reprod 49 522-527.

Wolf E, Arnold GJ, Bauersachs S, Beier HM, Blum H, Einspanier R, Frohlich T, Herrler A, Hiendleder S, Kolle $S$, Prelle K, Reichenbach HD, Stojkovic M, Wenigerkind H \& Sinowatz F 2003 Embryo-maternal communication in bovine-strategies for deciphering a complex cross-talk. Reprod Domest Anim 38 276-289.

Wu B, Ignotz GG, Currie WB \& Yang X 1996 Temporal distinctions in the synthesis and accumulation of proteins by oocytes and cumulus cells during maturation in vitro of bovine oocytes. Mol Reprod Dev 45 560-565.

Yamanaka Y, Ralston A, Stephenson RO \& Rossant J 2006 Cell and molecular regulation of the mouse blastocyst. Dev Dyn 235 2301-2314.

Yang J, Winkler K, Yoshida M \& Kornbluth S 1999 Maintenance of G2 arrest in the Xenopus oocyte: a role for 14-3-3-mediated inhibition of Cdc25 nuclear import. Embo i 18 2174-2183.

You J, Kim J, Lee H, Hyun SH, Hansen PJ \& Lee E 2012a MG132 treatment during oocyte maturation improves embryonic development after somatic cell nuclear transfer and alters oocyte and embryo transcript abundance in pigs. Mol Reprod Dev 79 41-50.

You J, Lee E, Bonilla L, Francis J, Koh J, Block J, Chen S \& Hansen PJ 2012b Treatment with the proteasome inhibitor MG132 during the end of oocyte maturation improves oocyte competence for development after fertilization in cattle. PLoS One 7 e48613.

Yurttas P, Morency E \& Coonrod SA 2010 Use of proteomics to identify highly abundant maternal factors that drive the egg-to-embryo transition. Reproduction 139 809-823. 